\title{
Distal Pancreatic Resection for Neuroendocrine Tumors: Is Laparoscopic Really Better than Open?
}

\author{
Dimitrios Xourafas • Ali Tavakkoli • Thomas E. Clancy • \\ Stanley W. Ashley
}

Received: 30 September 2014 / Accepted: 25 February 2015 /Published online: 11 March 2015

(C) 2015 The Author(s). This article is published with open access at Springerlink.com

\begin{abstract}
Background The latest studies on surgical and cost-analysis outcomes after laparoscopic distal pancreatectomy (LDP) highlight mixed and insufficient results. Whereas several investigators have compared surgical outcomes of LDP vs. open distal pancreatectomy (ODP) for adenocarcinomas, few similar studies have focused on pancreatic neuroendocrine tumors (PNETs). Methods We reviewed the medical records of PNET patients undergoing distal pancreatectomy between 2004 and 2014. Patients were divided into LDP vs. ODP groups. Demographics, relevant comorbidities, oncologic variables, and cost-analysis data were assessed. Survival and Cox proportional hazards analyses were used to evaluate outcomes.

Results Of the 171 distal pancreatectomies for PNETs, 73 were laparoscopic, whereas 98 were open. Patients undergoing LDP demonstrated significantly lower rates of postoperative complications $(P=0.028)$ and had significantly shorter hospital stays $(P=$ $0.008)$. On multivariable analysis, positive resection margins $(P=0.046), \mathrm{G} 3$ grade $(P=0.036)$, advanced WHO classification $(P=0.016)$, TNM stage $(P=0.018)$, and readmission $(P=0.019)$ were significantly associated with poor survival; however, method of resection (LDP vs. ODP) was not $(P=0.254)$. The median total direct costs of LDP vs. ODP did not differ significantly. Conclusions In response to the recent considerable controversy surrounding the costs and surgical outcomes of LDP vs. ODP, our results show that LDP for PNETs is cost-neutral and significantly reduces postoperative morbidity without compromising oncologic outcomes and survival.
\end{abstract}

Keywords Pancreatic neuroendocrine tumors $\cdot$ Distal pancreatectomy $\cdot$ Laparoscopic pancreatectomy

\section{Introduction}

Pancreatic neuroendocrine tumors (PNETs) are rare, representing approximately $2-4 \%$ of all pancreatic tumors with an incidence of $2-3$ cases per million people. ${ }^{1,2}$ In

Different abstracts from this manuscript were presented at Massachusetts Chapter of the American College of Surgeons, Boston, MA, December 2012 and Harvard Surgery Research Day Symposium, Boston, MA, May 2013.

D. Xourafas $(\triangle)$

Harvard School of Public Health, Boston, MA, USA

e-mail: dxourafas@partners.org

D. Xourafas · A. Tavakkoli • T. E. Clancy $\cdot$ S. W. Ashley Brigham and Women's Hospital, Harvard Medical School, Boston, MA, USA contrast to pancreatic adenocarcinoma, PNETs encompass a wider biological spectrum, which grants them a poorly defined natural history and often a challenging prognosis. ${ }^{3,4}$ Surgery is the standard curative modality for PNETs; however, surgical and oncologic outcomes vary significantly depending on whether the tumor is single or multiple, benign or malignant, functioning or nonfunctioning or whether resectable metastatic disease to the liver is present. ${ }^{3-5}$ Laparoscopic distal pancreatectomy (LDP) is well suited for complete radical resection of PNETs located in the pancreatic body or tail, at least for tumors that are relatively small and solitary.

Compared to open distal pancreatectomy (ODP), LDP performed in well-selected groups of pancreatic lesions has been confirmed to have superior results in terms of intraoperative blood loss, postoperative pain, time to recovery, and length of hospital stay (LHS). ${ }^{6-9}$ Despite these findings, latest reports on surgical outcomes of LDP vs. ODP highlight relevant inconsistencies between the two techniques. These inconsistencies involve operating time, rates of postoperative 
complications, pancreatic fistula, spleen preservation and conversion, costs, but more importantly, oncologic outcomes. ${ }^{10,11}$

Several investigators claim that the results of the surgical outcomes of LDP, as opposed to ODP, are neither clearly demonstrated nor generalizable due to underpowered existing comparative studies, introduction of important selection biases, and the nationwide underuse of laparoscopic pancreatectomy. ${ }^{12-14}$ Additionally, little data exist on longterm oncologic outcomes and mortality rates between LDP vs. ODP; therefore, studies with larger sample sizes and longer follow-ups are needed to clarify these issues. ${ }^{10,11}$ In an era of limited resources, concerns have been also raised about increasing costs for the laparoscopic approach, due to prolonged operating time and the relatively high cost of disposable surgical devices. ${ }^{15}$

Many reports on surgical outcomes after LDP vs. ODP have focused exclusively on well-selected subsets of pancreatic lesions to ensure homogeneous sampling, especially given that tumor factors may affect a patient's suitability for laparoscopic resection. ${ }^{16,17}$ These comparative cohorts have predominately analyzed LDP vs. ODP outcomes for pancreatic adenocarcinoma. Few large series have assessed similar outcomes for PNETs due to their heterogeneity and complex patterns of clinical behavior, which cause significant variability in oncologic outcomes and survival. ${ }^{4,5,18}$ To clarify mixed findings and to address recent salient controversies regarding postoperative, oncologic, and cost-analysis outcomes after LDP vs. ODP, we focused on a subset of PNET patients who underwent distal pancreatectomy at our institution.

\section{Materials and Methods}

The study was approved by our Institutional Review Board (IRB). International Classification of Disease (ICD)-9 codes for PNETs were identified from the Research Patient Data Registry (RPDR). A selected subset of patients with surgically resected, pathologically confirmed PNETs between July 2004 and 2014 were identified. After initial review of medical records, we excluded from the final analysis patients with multiple endocrine neoplasia type I or Von Hippel-Lindau disease, given their association with multiple other neoplasms that require more than pancreatic resection for cure.

Descriptive data were collected by review of patient's medical records. Preoperative variables included age, gender, race, and relevant comorbidities, such as history of smoking, alcohol use, and diabetes mellitus. Patients with signs, symptoms, and biochemical evidence of pancreatic hormonal excess were considered to have functioning tumors, which were histopathologically confirmed after resection, whereas patients with no recognizable clinical syndrome and normal serum hormone levels were considered to have nonfunctioning tumors. Preoperative assessment of serum Chromogranin A levels were also recorded using a cutoff range of $84-87 \mathrm{U} / \mathrm{L}$ to obtain a high specificity for PNETs. ${ }^{19}$ Operations were grouped as LDP vs. ODP with or without spleen preservation or liver resection.

Detailed baseline information on PNETs included tumor diameter and location. Distant metastasis was defined as liver metastases when only the liver was involved and liver and extra-hepatic metastases when bone, lung, or brain metastases were additionally demonstrated. Pathological characteristics included tumor grade, lymphovascular invasion, regional lymph node status, and resection margin status, which were determined from final pathology reports. Tumors were classified according to the World Health Organization system $(\mathrm{WHO})^{20}$ and staged according to the TNM scheme, which has been proposed by the European Neuroendocrine Tumor Society (ENETS). ${ }^{21}$

Postoperative complications were gathered from daily progress notes and discharge summaries. Postoperative pancreatic fistula (POPF) was assessed in $98 \%$ of patients in this cohort and defined as abdominal drainage with an amylase level $>3$ times the upper limit of normal after postoperative day number 3, according to the International Study Group on Pancreatic Fistula (ISGPF) recommendations. POPFs were additionally graded based on the ISGPF criteria as follows: biochemical fistulas without clinical sequelae were graded as A. Those requiring any therapeutic intervention were graded as B, and fistulas with severe clinical sequelae were graded as C. ${ }^{22}$ Abscess was diagnosed when culture-positive purulent drainage from an intra-abdominal fluid collection was obtained percutaneously or operatively and/or when fluid collection with systemic or localized signs of infection was confirmed radiologically. Wound infection was defined as any wound that required opening or antibiotics beyond standard prophylaxis.

$\mathrm{R} 0$ resection was considered when the primary tumor was removed with negative margins. Patients with microscopically or grossly positive margins were classified as having had an $\mathrm{R} 1$ or $\mathrm{R} 2$ resection, respectively. Conversion was defined as the need for an abdominal incision to deal with any intraoperative complication and allow completion of the case. LHS was calculated from date of operation to date of hospital discharge. Readmission was defined as re-hospitalization within 30 days from discharge. Perioperative mortality was defined as death within 30 days from the operation, or within the original hospital admission. Survival was calculated from the date of operation through the date of last follow-up.

For cost-analysis purposes, standard tariffs set by our hospital independent coding and costing committee were adopted. The cost per patient visit was retrieved using recorded information by patient medical record number, and specific visit number using the institution's financial cost accounting system. Total direct costs were defined as the median cost across cases in each group, and included all costs associated 
with the inpatient encounter, from admission to discharge for all hospital services provided. For both the LDP and ODP groups, cost analysis included the following:

- Operating room (OR) time in minutes, which was defined as the time from which the patient entered the operating room to the time at which he exited

- OR costs including team costs driven by the duration of the case, supplies, and recovery room costs

- Intra- and postoperative blood transfusion requirement costs

- Nursing, pharmacy, and laboratory testing costs

- Postoperative imaging costs including radiological reintervention within the same hospitalization

Other costs included anesthesia, cardiac noninvasive testing, emergency department costs, gastrointestinal endoscopy, nutrition services, OR special charges, physical and occupational therapy, radiation therapy, and respiratory/pulmonary therapy costs. Indirect costs were excluded from our calculations.

The 11 laparoscopic cases, which were converted to open, were classified under the LDP category according to an intentto-treat analysis framework. Continuous variables were compared using Student's $t$ test or Wilcoxon rank-sum test, whereas categorical variables were compared using Pearson's chi-squared test or Fisher's exact test as appropriate. Survival probability was estimated using the Kaplan-Meier method and compared using the log-rank test. Univariate and multivariable analyses were performed using Cox proportional hazards models. For cost analysis, we compared ratios of median costs for each cost category and reported the percentage of change in median cost. Continuous variables are reported as mean \pm standard deviation or median and range. Categorical variables are presented as numbers $(n)$ and percentages (\%). A $P$ value of less than 0.05 was considered statistically significant. Statistical analyses were conducted using the SAS statistical software program version 9.2 (SAS Institute, Cary, NC).

\section{Results}

We compared 73 PNET patients who underwent LDP to 98 patients who underwent ODP.

\section{Demographics and Clinical Characteristics}

Demographics and clinical characteristics are described in Table 1 . The median age of the entire cohort was 61 years (range 20-95) with 89 male (52\%) and 153 Caucasian patients $(89 \%)$. There were no statistically significant
Table 1 Demographics and clinical characteristics of PNET patients undergoing distal pancreatic resection and location and size of their tumors

\begin{tabular}{|c|c|c|c|}
\hline & $\begin{array}{l}\mathrm{LDP} \\
(n=73)\end{array}$ & $\begin{array}{l}\text { ODP } \\
(n=98)\end{array}$ & $P$ value \\
\hline Median age, $n$ (range) & $61(20-95)$ & $62(34-92)$ & 0.334 \\
\hline Male gender, $n(\%)$ & $41(56 \%)$ & $48(49 \%)$ & 0.358 \\
\hline \multicolumn{4}{|l|}{ Race, $n(\%)$ : } \\
\hline Caucasian & $64(88 \%)$ & $89(91 \%)$ & 0.616 \\
\hline African American & $2(3 \%)$ & $3(3 \%)$ & 0.901 \\
\hline Hispanic & $2(3 \%)$ & $1(1 \%)$ & 0.397 \\
\hline Asian & $5(6 \%)$ & $5(5 \%)$ & 0.630 \\
\hline Median BMI, $n$ & 27.8 & 28.4 & 0.756 \\
\hline History of smoking, $n(\%)$ & $21(28 \%)$ & $31(31 \%)$ & 0.687 \\
\hline Alcohol use, $n(\%)$ & $20(27 \%)$ & $22(22 \%)$ & 0.457 \\
\hline Diabetes, $n(\%)$ & $12(16 \%)$ & $13(13 \%)$ & 0.561 \\
\hline \multicolumn{4}{|l|}{ Tumor type, $n(\%)$ : } \\
\hline Nonfunctioning & $64(88 \%)$ & $70(72 \%)$ & 0.010 \\
\hline Insulinoma & $8(11 \%)$ & $21(21 \%)$ & 0.098 \\
\hline Gastrinoma & $1(1 \%)$ & $4(4 \%)$ & 0.297 \\
\hline Glucagonoma & 0 & $2(2 \%)$ & 0.507 \\
\hline ACTHoma & 0 & $1(1 \%)$ & 0.386 \\
\hline \multicolumn{4}{|c|}{ Presence of signs or symptoms, $n(\%)$ : } \\
\hline Asymptomatic & $52(72 \%)$ & $50(51 \%)$ & 0.007 \\
\hline Palpitations & 0 & $1(1 \%)$ & 0.386 \\
\hline Diarrhea & 0 & $4(4 \%)$ & 0.080 \\
\hline GI ulcers & $1(1 \%)$ & 0 & 0.426 \\
\hline Migratory erythema & 0 & $1(1 \%)$ & 0.386 \\
\hline Weight gain & 0 & $1(1 \%)$ & 0.386 \\
\hline Vague abdominal pain & $9(12 \%)$ & $18(18 \%)$ & 0.284 \\
\hline Weight loss & $3(4 \%)$ & $1(1 \%)$ & 0.186 \\
\hline Jaundice & $1(1 \%)$ & 0 & 0.426 \\
\hline Hypoglycemia & $7(10 \%)$ & $19(20 \%)$ & 0.077 \\
\hline Hyperglycemia & 0 & $1(1 \%)$ & 0.386 \\
\hline Fatigue & 0 & $2(2 \%)$ & 0.507 \\
\hline $\begin{array}{l}\text { High Chromogranin A levels, } \\
n(\%)\end{array}$ & $28(38 \%)$ & $34(35 \%)$ & 0.622 \\
\hline Median lesion size, cm (range) & $2.2(0.2-13)$ & $2.7(0.4-15)$ & 0.056 \\
\hline \multicolumn{4}{|l|}{ Location, $n(\%)$ : } \\
\hline Body & $11(15 \%)$ & $22(22 \%)$ & 0.226 \\
\hline Tail & $62(85 \%)$ & $76(78 \%)$ & 0.246 \\
\hline
\end{tabular}

differences with respect to age, gender, race, body mass index (BMI), and relevant comorbidities between the two groups. Overall, 37 patients ( $22 \%$ ) had functioning tumors, including 29 insulinomas, 5 gastrinomas, 2 glucagonomas, and 1 adrenocorticotropic hormone (ACTH)-secreting tumor, whereas 134 patients $(78 \%)$ had nonfunctioning tumors. A statistically higher proportion of patients with functioning tumors underwent ODP, whereas those with nonfunctioning tumors more often underwent LDP $(P=0.010)$. 
Overall, 69 patients ( $40 \%$ ) were symptomatic. A significantly lower percentage of symptomatic patients underwent LDP ( 28 vs. $49 \%$, LDP vs. ODP respectively, $P=0.007$ ). Despite this, there were no statistically significant differences with regard to the type of symptoms between the two groups. Abdominal pain was most frequently present in patients undergoing LDP $(12 \%)$, whereas hypoglycemia was the most frequent symptom occurring in patients who had ODP (20\%). Sixty-two patients (36\%) had elevated serum Chromogranin A levels, but this was not significantly different between patients undergoing LDP vs. ODP ( 38 vs. $35 \%$, LDP vs. ODP, $P=0.622$ ).

\section{Tumor Size and Location}

The size and anatomic location of the resected PNETs are also described in Table 1. The median tumor diameter in patients undergoing LDP, as determined by pathology, was lower compared to the median tumor diameter of those who had ODP ( 2.2 vs. $2.7 \mathrm{~cm}$, LDP vs. ODP, $P=0.056$ ). Overall, 33 PNETs were located in the body of the pancreas (19\%), whereas 138 were located in the tail (81\%).

\section{Operations}

Overall, 171 distal pancreatectomies were performed. Fiftyone patients undergoing LDP required a splenectomy compared to 60 patients who underwent ODPs (61 vs. $69 \%$, LDP vs. ODP, $P=0.260)$. Seven patients $(4 \%)$ had a simultaneous liver resection, of which two were performed during LDP, whereas five during ODP (3 vs. $5 \%$, LDP vs. ODP, $P=0.700)$. In 11 patients $(15 \%)$, a laparoscopic procedure was converted to laparotomy: six procedures were converted due to deep adhesions, which prevented visibility, and five others were converted due to intraoperative bleeding that could not be controlled laparoscopically. Although the OR time of LDPs was shorter compared to the OR time for ODPs, such difference was not statistically significant (352 vs. $409 \mathrm{~min}$, LDP vs. ODP respectively, $P=0.065$ ).

\section{Pathologic Characteristics}

Fifty-four PNETs (74 \%) of patients undergoing LDP were low-grade, 15 intermediate-grade (20\%), and 4 high-grade $(6 \%)$ vs. 71 low-grade $(72 \%), 20$ intermediate-grade $(21 \%)$, and 7 high-grade $(7 \%)$ of those undergoing ODP (Table 2). Seventeen tumors resected with laparoscopic surgery $(23 \%)$ had microscopic evidence of lymphovascular invasion vs. 35 of those resected using the open technique (35\%). In the LDP group, 11 patients $(15 \%)$ had positive regional lymph nodes, and three patients $(4 \%)$ had distant metastases at the time of resection. In contrast, in the ODP group, 19 patients $(19 \%)$ had positive regional lymph nodes and 11 patients $(11 \%)$ had distant metastases. Five of the 14
Table 2 Pathologic characteristics of the 171 resected PNETs

\begin{tabular}{llll}
\hline & $\begin{array}{l}\text { LDP } \\
(n=73)\end{array}$ & $\begin{array}{l}\text { ODP } \\
(n=98)\end{array}$ & $P$ value \\
\hline Grade, $n$ (\%): & & & \\
$\quad$ Low (G1) & $54(74 \%)$ & $71(72 \%)$ & 0.824 \\
$\quad$ Intermediate (G2) & $15(20 \%)$ & $20(21 \%)$ & 0.982 \\
$\quad$ High (G3) & $4(6 \%)$ & $7(7 \%)$ & 0.760 \\
Lymphovascular invasion, $n(\%)$ & $17(23 \%)$ & $35(35 \%)$ & 0.094 \\
Positive lymph nodes, $n(\%)$ & $11(15 \%)$ & $19(19 \%)$ & 0.426 \\
Distant metastasis, $n$ (\%) & $3(4 \%)$ & $11(11 \%)$ & 0.093 \\
Positive resection margins, $n(\%)$ & $2(3 \%)$ & $7(7 \%)$ & 0.303 \\
WHO classification, $n(\%):$ & & & \\
$\quad$ Well-differentiated tumor (WDT) & $60(82 \%)$ & $72(74 \%)$ & 0.200 \\
$\quad$ Well-differentiated carcinoma & $9(12 \%)$ & $19(19 \%)$ & 0.296 \\
$\quad$ (WDCa) & & & \\
Poorly differentiated carcinoma & $4(6 \%)$ & $7(7 \%)$ & 0.760 \\
$\quad$ PDCa) & & & \\
TMN stage, $n$ (\%): & & & \\
$\quad$ Stage 1 & $34(47 \%)$ & $38(39 \%)$ & 0.348 \\
Stage 2 & $28(38 \%)$ & $37(38 \%)$ & 0.100 \\
Stage 3 & $8(11 \%)$ & $15(15 \%)$ & 0.499 \\
Stage 4 & $3(4 \%)$ & $8(8 \%)$ & 0.356 \\
\hline
\end{tabular}

patients with metastatic disease (36\%) underwent resection of their primary PNET only, whereas nine underwent synchronous liver resection or cryoablation (64\%). Overall, 162 patients $(95 \%)$ had complete resection (R0), whereas nine patients $(5 \%)$ had evidence of microscopic disease on the pancreatic margin (R1).

According to the WHO classification, 132 patients (77\%) had WDT ( 82 vs. $74 \%$, LDP vs. ODP, $P=0.200$ ), 28 patients $(16 \%)$ had WDCa (12 vs. $19 \%$, LDP vs. ODP, $P=0.296$ ), and 11 patients (6\%) had PDCa (6 vs. $7 \%$, LDP vs. ODP, $P=$ $0.760)$. In terms of TNM stage, overall 72 patients $(42 \%)$ had stage 1 disease, 65 patients (38\%) stage 2, 23 patients (13\%) stage 3 , and 11 patients (7\%) stage 4 disease. Although the LDP group had more WDTs and lower stages of disease, the two groups did not differ significantly in terms of pathologic characteristics of their tumors (Table 2).

\section{Postoperative and Oncologic Outcomes}

The overall surgical morbidity in terms of postoperative complications was $40 \%$. Sixteen patients $(9 \%)$ required reoperation due to: incisional hernia $(n=5)$, tumor recurrence $(n=7)$, necrotizing pancreatitis associated with intra-abdominal abscess $(n=2)$, small bowel obstruction $(n=1)$, and persistent pancreatic leak associated with hemorrhage $(n=1)$. Twentyone patients $(12 \%)$ required readmission for the treatment of postoperative complications. Overall, there was one perioperative death (1.02\%) after ODP for WDCa. 
For the entire cohort, the median LHS was 6 days (range of 3-39) and the median follow-up was 41 months (range of 2254). There were no statistically significant differences in terms of follow-up between the two groups ( 32 vs. 44 months, LDP vs. ODP, $P=0.371)$. During this time, overall seven patients $(4 \%)$ developed recurrences. Five patients had a tumor recurrence in the liver, whereas two patients had recurrences in the liver and pancreatic bed. Recurrences occurred between a minimum of 17 and 108 months. The 5-year survival for the entire cohort was $95 \%$. The 5-year survival for patients with WDT, WDCa, and PDCa was 98.4, 71.4, and 36.3\%, respectively $(P<0.001$, Fig. 1$)$. The 5-year survival for patients with TNM stages $1,2,3$, and 4 was 98.6, 95.3, 73.9, and $36.3 \%$, respectively $(P<0.001$, Fig. 2$)$. Type of surgery (LDP vs. ODP) did not influence the 5-year survival (log-rank test, $P=0.254$, Fig. 3).

Although the most frequent major postoperative complication in both groups was POPF, we had no statistically significant differences in terms of frequency of occurrence (22 vs. $33 \%$, LDP vs. ODP, $P=0.168$ ) or severity grade (grade A, 16 vs. $18 \%$, LDP vs. ODP, $P=0.840$ ) between the two groups (Table 3). Despite having no significant differences with respect to individual type of complications (pancreatic fistula, incisional hernia, intra-abdominal collection, bowel obstruction, or superficial or deep would infection) between the LDP and ODP groups, we observed statistically significant differences in the overall rates of postoperative complications: fewer patients undergoing LDP developed postoperative complications (30 vs. $47 \%$, LDP vs. ODP, $P=0.028$, Table 3 ).

Additionally, for the entire cohort, we had no statistically significant differences between the two groups in terms of readmission rates ( 12 vs. $19 \%$, LDP vs. ODP, $P=0.296)$ or reoperation ( 8 vs. $10 \%$, LDP vs. ODP, $P=0.659$ ). There were no perioperative deaths in the LDP group, but there was one death $(1.02 \%)$ in the ODP group $(P=0.386)$. Patients who underwent LDP had a significantly shorter median LHS than those undergoing ODP [5 days (range of 3-18) vs. 7 days (range of 4-39), LDP vs. ODP, $P=0.008]$. With a median follow-up of 32 months (range of 3-185), three patients in the LDP group (4\%) developed a recurrence. Similarly, with a median follow-up of 44 months (range of 2-254), four patients in the ODP group (4\%) developed recurrences $(P=0.992)$. During follow-up, four patients $(5 \%)$ in the LDP group died vs. 13 patients $(13 \%)$ in the ODP group $(P=0.122)$, (Table 3).

Potential Predictors of Poor Survival in Patients with PNETs

Additionally, we performed an analysis of potential prognostic factors impacting survival after distal pancreatic resection for PNETs. On univariate analysis (Table 4), tumor size $>3 \mathrm{~cm}$ $(P=0.041)$ and positive resection margins $(P=0.016)$ predicted poor survival. Furthermore, tumor grade G-3 vs. G-1 $(P=0.041)$, WDCa $(P=0.003)$ and PDCa $(P<0.001)$ vs. WDT by WHO classification, and stages $3(P=0.014)$ and 4 $(P<0.001)$ vs. stage 1 by TMN, were also significantly associated with poor survival. In contrast, age $>60$ years $(P=0.231)$, male gender $(P=0.223)$, Caucasian race $(P=$ $0.983)$, presence of symptoms $(P=0.937)$, functioning tumor type $(P=0.954)$, tumor location (either body or tail, $P=0.839$ ), type of resection (LDP vs. ODP, $P=0.479)$, presence of postoperative complications $(P=0.390)$, readmission $(P=0.491)$, reoperation $(P=0.689)$, and recurrence $(P=0.996)$ did not correlate with poor survival.
Fig. 1 Kaplan-Meier estimates of survival for patients who underwent R0/R1 distal resection for PNETs. Five-year survival estimates stratified by WHO classification for patients with WDT, WDCa, and PDCa were $98.4,71.4$, and $36.3 \%$, respectively (log-rank test, $P<0.001)$

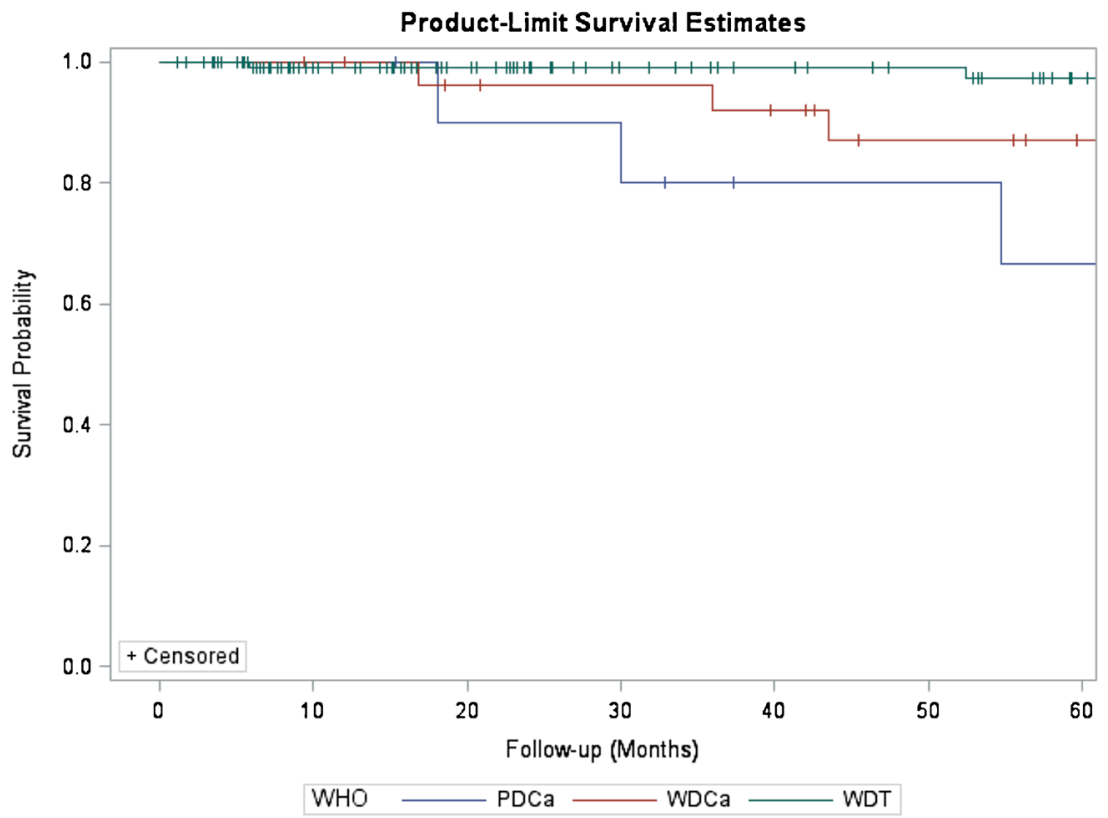


Fig. 2 Five-year survival estimates stratified by ENETS-

TNM stage for patients with stages $1,2,3$, and 4 disease were 98.6, 95.3, 73.9, and $36.3 \%$, respectively (log-rank test, $P<0.001)$

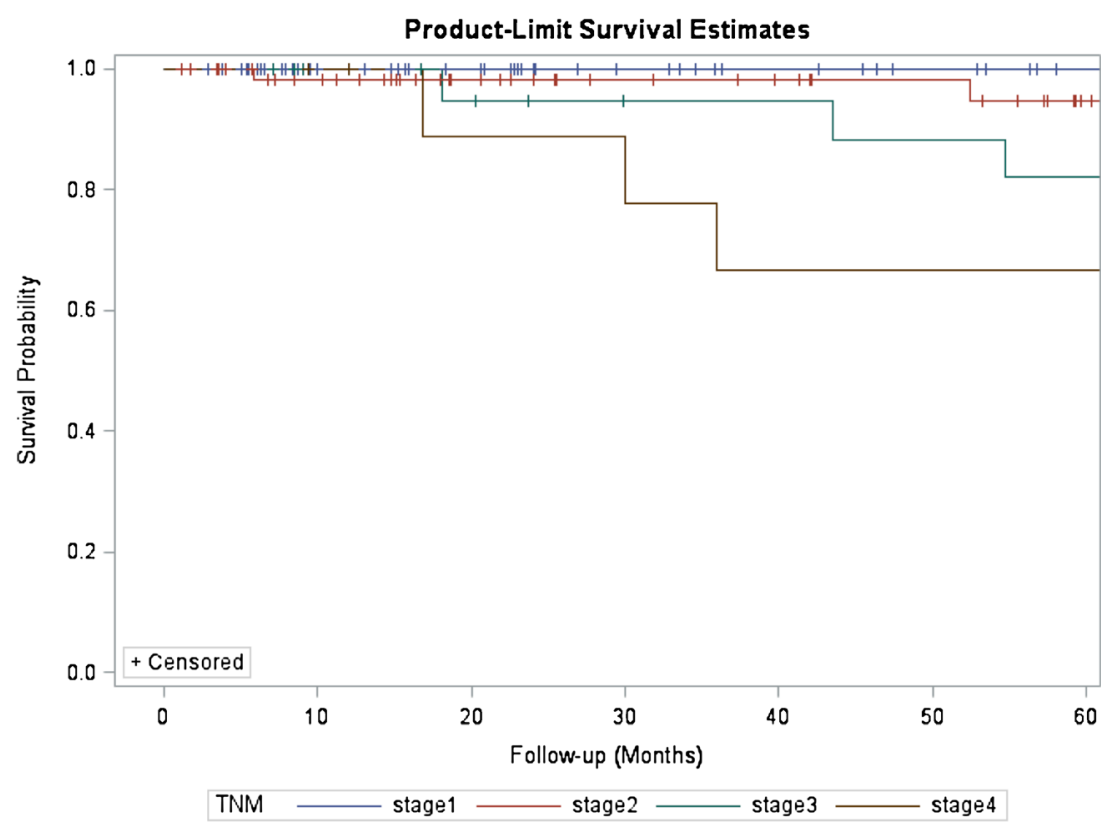

On multivariable analysis when controlling for demographics and clinical characteristics-including age, gender, presence of symptoms, and functioning tumor type- positive resection margins $(P=0.046)$, tumor grade G-3 $(P=0.036)$, poorly differentiated tumors [WDCa $(P=0.002)$ and PDCa $(P=0.016)]$, TNM stage $3(P=0.032)$, TNM stage $4(P=$ $0.018)$, and readmission $(P=0.019)$ remained significantly associated with poor survival (Table 5). On multivariable analysis, tumor $>3 \mathrm{~cm}$ was no longer associated with poor survival $(P=0.475)$.
Case Costing

Complete data from 123 PNET patients-56 who underwent LDP and 67 who underwent ODP - were available for analysis. The breakdown of the operative and hospital costs are described in Table 6. The LDP and ODP cohorts did not differ significantly in terms of median OR minutes (352 vs. $409 \mathrm{~min}$, LDP vs. ODP, $P=0.065$ ). Although the median total direct costs for the LDP group were $20 \%$ lower, compared to the ODP group, this was not statistically significant $(P=0.179)$.
Fig. 3 Kaplan-Meier estimates of survival for patients who underwent LDP vs. ODP for PNETs. Type of surgery (LDP vs. ODP) did not influence 5-year survival (log-rank test, $P=0.254$ )

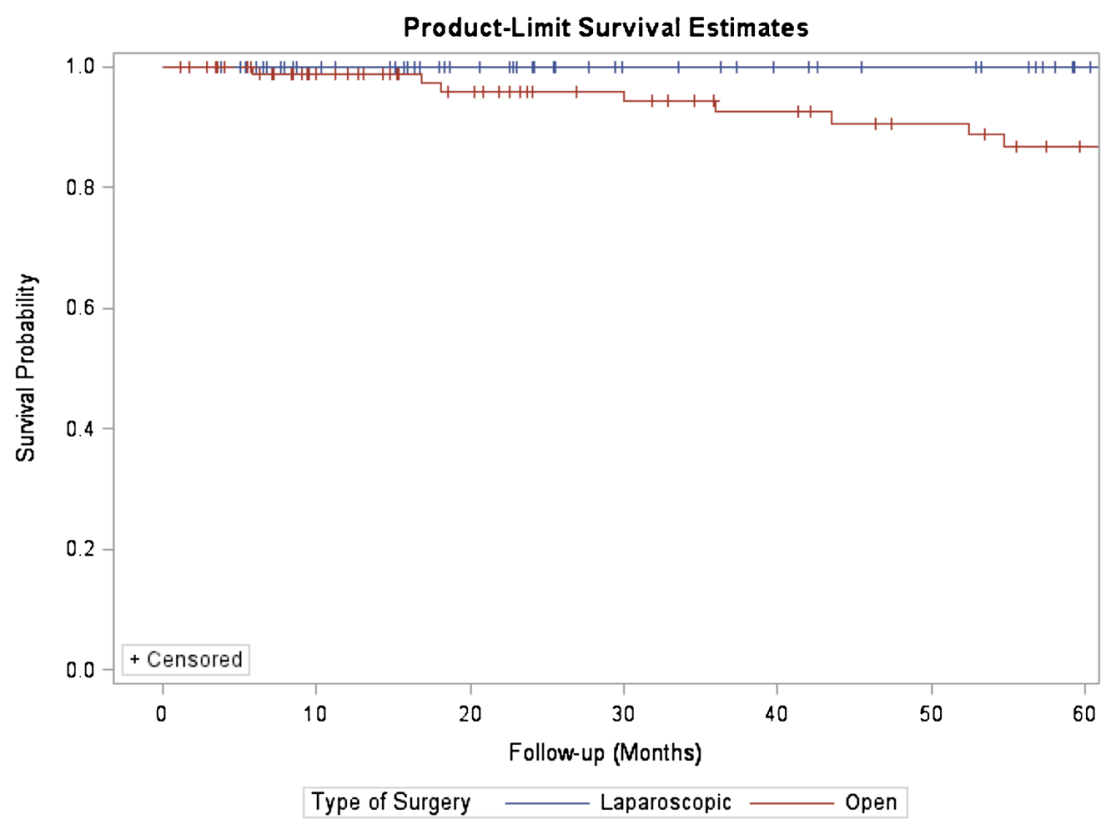


Table 3 Postoperative outcomes for LDP vs. ODP for PNETs

\begin{tabular}{|c|c|c|c|}
\hline & $\begin{array}{l}\text { LDP } \\
(n=73)\end{array}$ & $\begin{array}{l}\text { ODP } \\
(n=98)\end{array}$ & $P$ value \\
\hline \multicolumn{4}{|l|}{ Complications, $n(\%)$ : } \\
\hline Uncomplicated & $51(70 \%)$ & $52(53 \%)$ & 0.028 \\
\hline $\begin{array}{l}\text { Postoperative pancreatic fistula } \\
\text { (POPF) }\end{array}$ & $16(22 \%)$ & $32(33 \%)$ & 0.168 \\
\hline Incisional hernia & 0 & $5(5 \%)$ & 0.072 \\
\hline Intra-abdominal collection/abscess & $6(8 \%)$ & $5(5 \%)$ & 0.531 \\
\hline Bowel obstruction & 0 & $2(2 \%)$ & 0.507 \\
\hline $\begin{array}{l}\text { Wound infection (superficial } \\
\text { or deep) }\end{array}$ & 0 & $2(2 \%)$ & 0.507 \\
\hline \multicolumn{4}{|l|}{ ISGPF pancreatic fistula, $n(\%)$ : } \\
\hline Grade A & $12(16 \%)$ & $18(18 \%)$ & 0.840 \\
\hline Grade B & $4(6 \%)$ & $12(13 \%)$ & 0.185 \\
\hline Grade C & 0 & $2(2 \%)$ & 0.507 \\
\hline Readmission, $n(\%)$ & $9(12 \%)$ & $19(19 \%)$ & 0.296 \\
\hline Reoperation, $n(\%)$ & $6(8 \%)$ & $10(10 \%)$ & 0.659 \\
\hline Overall mortality, $n(\%)$ & $4(5 \%)$ & $13(13 \%)$ & 0.122 \\
\hline Median LHS, days (range) & $5(3-18)$ & $7(4-39)$ & 0.008 \\
\hline Median follow-up, months (range) & $32(3-185)$ & $44(2-254)$ & 0.371 \\
\hline Recurrence, $n(\%)$ & $3(4 \%)$ & $4(4 \%)$ & 0.992 \\
\hline
\end{tabular}

Table 4 Univariate analysis of PNETs - clinicopathologic factors and survival

\begin{tabular}{llll}
\hline Variable & $\begin{array}{l}\text { Hazard ratio } \\
\text { (HR) }\end{array}$ & HR CI for & $P$ value \\
& 0.556 & $0.213-1.454$ & 0.231 \\
Age $(>60)$ & 1.847 & $0.688-4.956$ & 0.223 \\
Male & 1.016 & $0.221-4.667$ & 0.983 \\
Caucasian & 0.961 & $0.357-2.586$ & 0.937 \\
Presence of symptoms & 0.970 & $0.339-2.773$ & 0.954 \\
Functioning tumor type & 4.681 & $1.065-20.572$ & 0.041 \\
Tumor size $>3$ cm & 2.805 & $0.366-2.477$ & 0.839 \\
Tumor location (tail) & 1.513 & $0.480-4.771$ & 0.479 \\
Open surgery & 1.210 & $0.412-3.551$ & 0.728 \\
High Chromogranin A levels & 4.060 & $1.288-12.799$ & 0.016 \\
Positive resection margins & 3.029 & $1.044-8.790$ & 0.041 \\
High-grade tumor (G3) & 10.041 & $2.093-48.173$ & 0.003 \\
WDCa & 25.108 & $5.170-121.939$ & $<0.001$ \\
PDCa & 14.642 & $1.693-126.591$ & 0.014 \\
TMN stage 3 & 63.680 & $7.286-556.531$ & $<0.001$ \\
TMN stage 4 & 1.197 & $0.490-8.962$ & 0.356 \\
LHS $>15$ days & 1.523 & $0.583-3.978$ & 0.390 \\
Presence of postoperative & 1.448 & $0.505-4.152$ & 0.491 \\
$\quad$ complications & 1.291 & $0.368-4.529$ & 0.689 \\
Readmission & 1.004 & $0.130-7.760$ & 0.996 \\
Reoperation & & & \\
Presence of recurrence & & & \\
\hline & & & \\
\hline
\end{tabular}

Table 5 Multivariable analysis of PNETs - clinicopathologic factors and survival

\begin{tabular}{llll}
\hline Variable & $\begin{array}{l}\text { Hazard ratio } \\
\text { (HR) }\end{array}$ & $\begin{array}{l}95 \% \text { CI for } \\
\text { HR }\end{array}$ & $P$ value \\
\hline Tumor size $>3 \mathrm{~cm}$ & 0.475 & $0.143-1.580$ & 0.475 \\
Positive resection margins & 5.234 & $1.030-26.595$ & 0.046 \\
High-grade tumor (G3) & 4.276 & $1.099-16.638$ & 0.036 \\
WDCa & 13.050 & $2.432-70.041$ & 0.002 \\
PDCa & 9.237 & $1.505-56.679$ & 0.016 \\
TMN stage 3 & 16.173 & $1.258-207.994$ & 0.032 \\
TMN stage 4 & 18.127 & $1.628-201.869$ & 0.018 \\
Readmission & 11.860 & $1.522-92.398$ & 0.019 \\
\hline
\end{tabular}

Similarly, the median OR costs for the LDP group were $10.5 \%$ higher than the median OR costs for the ODP group, but still not statistically significant $(P=0.091)$. Detailed analysis of OR costs revealed no statistically significant differences in terms of recovery room costs between the two groups $(P=0.466)$, but median OR team and median supply costs were respectively $20 \%$ lower $(P=0.027)$ and $91.7 \%$ higher $(P<0.001)$ for the LDP group. Median blood, nursing and laboratory costs were, respectively, 24.4, 25.6, and $38.4 \%$ lower in the LDP group, and despite the statistical significance, this did not generate differences in the total direct costs between the groups. The remaining hospital costs, including costs for pharmaceuticals $(P=0.154)$, imaging $(P=0.526)$, and other costs $(P=0.317)$, were not significantly different between the two groups (Table 6).

Table 6 Breakdown of ratio and percentage change in median costs between LDP and ODP for PNETs

\begin{tabular}{llll}
\hline Variable & $\begin{array}{l}\text { Ratio of } \\
\text { median cost } \\
\text { (LDP/ODP) }\end{array}$ & $\begin{array}{l}\text { \% change in } \\
\text { median cost } \\
\text { (LDP/ODP) }\end{array}$ & $P$ value \\
\hline Operating room minutes & 0.84 & $-13.5 \%$ & 0.065 \\
Total direct cost & 0.80 & $-20.0 \%$ & 0.179 \\
Operating room (OR) cost: & 1.12 & $10.5 \%$ & 0.091 \\
$\quad$ OR team & 0.81 & $-20.0 \%$ & 0.027 \\
$\quad$ Supplies & 1.93 & $91.7 \%$ & $<0.001$ \\
$\quad$ Recovery room & 0.83 & $-17.2 \%$ & 0.466 \\
Blood cost & 0.75 & $-24.4 \%$ & 0.020 \\
Nursing cost & 0.75 & $-25.6 \%$ & 0.048 \\
Pharmacy cost & 0.85 & $-15.3 \%$ & 0.154 \\
Laboratory cost & 0.61 & $-38.4 \%$ & 0.002 \\
Radiology cost & 0.52 & $-46.2 \%$ & 0.526 \\
Other cost & 0.97 & $-0.65 \%$ & 0.317 \\
\hline
\end{tabular}




\section{Discussion}

Many recent studies have shown that laparoscopic pancreatic surgery in well-selected groups of patients, as opposed to the open technique, is safe and associated with various equivalent or better surgical outcomes. ${ }^{5-9,23-26}$ However, there has been a steadily growing debate about the small size of these studies, the presence of significant selection biases, the lack of generalizability of results and the short-term follow-ups. ${ }^{10-14}$ In this study, we aim to put the controversy to rest on the impact of LDP for PNETs on postoperative, oncologic, and costanalysis outcomes.

Few large series have compared surgical outcomes of LDP vs. ODP for PNET patients. ${ }^{4,5,18}$ The vast majority of the PNETs in our study were nonfunctioning (78\%), which is consistent with other reports in the literature. ${ }^{18}$ Of the 37 patients with functioning PNETs, a significantly higher percentage underwent ODPs. In accordance with their functioning tumors, patients undergoing ODP were more often symptomatic, with abdominal pain and hypoglycemia being the most common presenting symptoms. Patients with smaller neoplasms were more frequently chosen for LDP, which is commonly observed in previous similar reports. 5,12

With regard to intraoperative outcomes, many series have shown that the duration of LDP is significantly longer when compared to ODP. ${ }^{6,15,27-29}$ However, our results show no significant differences between the duration of the two approaches. Discrepancies regarding surgical case duration may be attributed to differences in tumor size as well as differences regarding the various stages of disease, which may require a more or less extensive resection. Despite not having statistically significant differences between the LDP and ODP groups in terms of spleen preservation, our splenectomy rates were lower in the LDP group. Lower splenectomy rates after LDP reached a statistical significance in recent similar comparative series. ${ }^{10,14}$ This might be explained by a planned splenectomy due to higher rates of malignancy in the ODP group; in which case, proximity of tumor to the splenic vasculature often makes preservation difficult. Based on the literature, conversion rates of LDP may vary significantly. In this study, conversion rates were significantly lower compared to other series. ${ }^{14,30}$ This might be explained by our low rate of intraoperative complications in addition to the relative ease of identifying PNETs without needing intraoperative ultrasound. However, high rates of conversion highlight the demand for specific training in LDP.

Recent studies show no significant differences in terms of postoperative morbidity between the two techniques. $5,11,13-15,28$ However, some of these studies are not specific and include both benign and malignant pancreatic lesions. In contrast, our data support that PNET patients undergoing LDP have significantly lower rates of overall postoperative complications, including POPF, incisional hernia, intra-abdominal collection or abscess, bowel obstruction, and superficial or deep wound infection. Without reaching statistical significance, we observed that the LDP group experienced fewer POPFs compared to the ODP group, which is conflicting with recent results obtained by other investigators. ${ }^{10,11,13,14}$ However, some of these reports are underpowered, and others are large meta-analyses, which include studies of suboptimal quality. Moreover, in these studies, there is significant inconsistency regarding the definition of POPF and differences between the clinical grading of POPFs were not always assessed. Therefore, the real advantage of LDP on the rates of POPF remained an open issue. Our LDP group was also associated with less intraoperative blood loss and had significantly shorter hospital stays when compared to the ODP group. This short hospital stay favored accelerated recovery and simultaneously contributed to lowering the costs of hospitalization. Our analysis failed to demonstrate any significant differences between the two groups with regard to postoperative mortality, recurrence, reoperation, or readmission rates. Other comparative cohorts have recently reported no significant differences in terms of intraoperative blood loss and LHS, ${ }^{6-9}$ as well as similar rates of readmission and 30-day mortality. 5,12

It has been frequently suggested that LDP has similar or even superior oncologic outcomes compared to the open technique, such as rates of $\mathrm{R} 0$ resections and survival; however, most of these studies are relatively small cohorts $(<30$ patients), they are often composed of nonhomogeneous samples in terms of patient and tumor characteristics, and assess only 2- or 3-year survival rates. $5,6,10,11,13,16,28,29$ A recent study shows that LDP for pancreatic adenocarcinoma does not compromise perioperative oncologic outcomes, but diseasespecific and overall survival data are lacking. ${ }^{12}$ In contrast, our study is composed of 171 patients, all of whom were diagnosed with PNETs and 5-year survival rates are assessed. In analyzing oncologic outcomes between the two techniques, it is also crucial to note that we had no statistically significant differences in pathology between patients undergoing LDP vs. ODP. In contrast, in many similar series, the pathological characteristics between the two groups were significantly different. For example, the minimally invasive group had significantly smaller, lower grade tumors with less lymphovascular invasion, fewer regional nodal metastases, more welldifferentiated tumors and lower stages of disease. ${ }^{5,12,16}$ Such relevant differences in pathology constitute the main reasons why recent comparative studies debate existing findings on the oncologic equivalency of the two techniques. , $^{6,31-33}$

The overall survival rate of the PNET patients in our cohort (90\%) is similar to other reports, where survival ranges between 65 and $90 \%$ and was not significantly different between the LDP and ODP groups. ${ }^{27,34}$ Five-year survival rates were similar using the WHO and ENETS-TNM classification systems and was not influenced by type of resection-LDP 
vs. ODP. Nine patients with a WDCa and four patients with a PDCa underwent R0 LDP without postoperative morbidity or mortality at 5 years. Only one of these patients developed a tumor recurrence at 21 months from surgery and was alive at the conclusion of study follow-up, at 8 years from surgery. Overall, three patients in the LDP group (4\%) developed a recurrence after R0 resection. Additionally, three patients in the LDP group - two of whom had WDTs and one with $\mathrm{PDCa}$ - developed liver metastases, which were treated with chemotherapy, and two of these patients were alive at the conclusion of study follow-up.

Along with the classification and staging of PNETs, we have examined pathologic characteristics that predicted poor survival. Using univariate analysis, we found that tumors $>3 \mathrm{~cm}$ in diameter, high-grade tumors (G3), as well as positive resection margins predicted poor survival. Consistent with other data published, ${ }^{27,35}$ we found that WDCa, PDCa, and TNM stages 3 and 4 were also statistically associated with poor survival. On multivariable analysis, when controlling for demographics and clinicopathologic characteristics, tumor size $>3 \mathrm{~cm}$ in diameter no longer correlated with poor survival; however, the remaining statistically significant factors on univariate analysis all maintained their significant association with poor survival. Interestingly, we found that 30-day readmission was a predictor of poor survival on multivariable analysis.

Although questions have been raised concerning the cost of the laparoscopic approach, large studies comparing direct costs after LDP vs. ODP are scarce. Therefore, the economic advantages of laparoscopic pancreatectomy are not settled. Comparative small-sized trials report similar total direct costs between LDP and ODP, ${ }^{8,36}$ but in contrast, a recent study shows that the laparoscopic approach is associated with extra cost. ${ }^{15}$ We demonstrated that LDP in comparison to ODP is cost-neutral. Although the total direct costs, including nursing, pharmacy, laboratory, and radiology costs were lower in the LDP than the ODP group, these were not statistically significant. Due to much higher supply expenses, median OR costs were higher for the laparoscopic group than the open approach, but still not significantly so.

As with any retrospective review, this study has several limitations. Although there were no statistically significant differences in pathologic characteristics between the two groups, smaller- and lower-grade PNETs without locoregional or distant metastases were selected for the laparoscopic approach. As a result, there are relatively more malignant tumors in the ODP group, though this is consistent with other reports. ${ }^{5,25}$ We additionally acknowledge the relative difficulty of comparing data in patients undergoing distal pancreatectomy, given that multiple factors may play into the decision to use the open or the laparoscopic approach. Lastly, our study population is defined by the demographics seen at our institution, a high-volume academic center with experienced pancreatic surgeons, and therefore results may be less applicable at other institutions.

\section{Conclusion}

We conducted this study to address the current significant controversy over the surgical outcomes of LDP vs. ODP as treatment for pancreatic cancer. Based on our research, LDP for PNETs presents similar long-term oncologic outcomes as compared to ODP, providing reduced overall morbidity in terms of postoperative complications without compromising survival. Advanced WHO classification and TNM stage, as well as positive resection margins, advanced tumor grade, and 30-day readmission are predictors of poor survival for PNET patients. Additionally, LDP is cost-neutral as opposed to the open approach and yields shorter hospital stays, less postoperative pain, better cosmetic results, and faster postoperative recovery. Larger prospective controlled trials are needed to further validate the advantages of LDP in well-selected groups of patients.

Open Access This article is distributed under the terms of the Creative Commons Attribution License which permits any use, distribution, and reproduction in any medium, provided the original author(s) and the source are credited.

\section{References}

1. Fendrich V, Bartsch DK(2011)Surgical treatment of gastrointestinal neuroendocrine tumors. Langenbecks Arch Surg 396(3):299-311

2. Yao JC, Hassan M, Phan A, Dagohoy C, Leary C, Mares JE, Abdalla EK, Fleming JB, Vauthey JN, Rashid A, Evans DB (2008) One hundred years after "carcinoid": epidemiology of and prognostic factors for neuroendocrine tumors in 35,825 cases in the United States. J Clin Oncol 26(18):3063-3072

3. Norton JA. Surgery for primary pancreatic neuroendocrine tumors. J Gastrointest Surg. 2006;10:327-331

4. Bilimoria KY, Talamonti MS, Tomlinson JS, Stewart AK, Winchester DP, Ko CY, Bentrem DJ. Prognostic score predicting survival after resection of pancreatic neuroendocrine tumors: analysis of 3851 patients. Ann Surg 2008;247:490-500.

5. DiNorcia J, Lee MK, Reavey PL, Genkinger JM, Lee JA, Schrope BA, Chabot JA, Allendorf JD. One hundred thirty resections for pancreatic neuroendocrine tumor: evaluating the impact of minimally invasive and parenchyma-sparing techniques. J Gastrointest Surg. 2010;14(10): 1536-46.

6. Song KB, Kim SC, Park JB, Kim YH, Jung YS, Kim MH, Lee SK, Seo DW, Lee SS, Park do H, Han DJ. Single-center experience of laparoscopic left pancreatic resection in 359 consecutive patients: changing the surgical paradigm of left pancreatic resection. Surg Endosc 2011;25:3364e3372.

7. Vijan SS, Ahmed KA, Harmsen WS, Que FG, Reid-Lombardo KM, Nagorney DM, Donohue JH, Farnell MB, Kendrick ML. Laparoscopic vs open distal pancreatectomy: a single-institution comparative study. Arch Surg 2010;145:616e621. 
8. Limongelli P, Belli A, Russo G, Cioffi L, D’Agostino A, Fantini C, Belli G. Laparoscopic and open surgical treatment of left-sided pancreatic lesions: clinical outcomes and cost-effectiveness analysis. Surg Endosc 2012;26:1830e1836.

9. Kim SC, Song KB, Jung YS, Kim YH, Park do H, Lee SS, Seo DW, Lee SK, Kim MH, Park KM, Lee YJ. Short-term clinical outcomes for 100 consecutive cases of laparoscopic pylorus-preserving pancreatoduodenectomy: improvement with surgical experience. Surg Endosc 2013;27:95e103.

10. Drymousis P, Raptis DA, Spalding D, Fernandez-Cruz L, Menon D, Breitenstein S, Davidson B, Frilling A. Laparoscopic versus open pancreas resection for pancreatic neuroendocrine tumours: a systematic review and meta-analysis. HPB (Oxford). 2014; 16(5):397-406.

11. Zhang Y, Chen XM, Sun DL. Laparoscopic versus open distal pancreatectomy: a single-institution comparative study. World J Surg Oncol. 2014;12(1):327.

12. Sharpe SM, Talamonti MS, Wang E, Bentrem DJ, Roggin KK, Prinz RA, Marsh RD, Stocker SJ, Winchester DJ, Baker MS. The laparoscopic approach to distal pancreatectomy for ductal adenocarcinoma results in shorter lengths of stay without compromising oncologic outcomes. Am J Surg. 2014 Dec 17.

13. Shin SH, Kim SC, Song KB, Hwang DW, Lee JH, Lee D, Lee JW, Jun E, Park KM, Lee YJ. A Comparative Study of Laparoscopic vs Open Distal Pancreatectomy for Left-Sided Ductal Adenocarcinoma: A Propensity Score-Matched Analysis. J Am Coll Surg. 2015;220(2): 177-85.

14. de Rooij T, Jilesen AP, Boerma D, Bonsing BA, Bosscha K, van Dam RM, van Dieren S, Dijkgraaf MG, van Eijck CH, Gerhards MF, van Goor H, van der Harst E, de Hingh IH, Kazemier G, Klaase JM, Molenaar IQ, Nieveen van Dijkum EJ, Patijn GA, van Santvoort HC, Scheepers JJ, van der Schelling GP, Sieders E, Vogel JA, Busch OR, Besselink MG; Dutch Pancreatic Cancer Group. A Nationwide Comparison of Laparoscopic and Open Distal Pancreatectomy for Benign and Malignant Disease. J Am Coll Surg. 2014 Nov 20.

15. Braga M, Pecorelli N, Ferrari D, Balzano G, Zuliani W, Castoldi R. Results of 100 consecutive laparoscopic distal pancreatectomies: postoperative outcome, cost-benefit analysis, and quality of life assessment. Surg Endosc. 2014 Oct 8. [Epub ahead of print]

16. Kooby DA, Hawkins WG, Schmidt CM, Weber SM, Bentrem DJ, Gillespie TW, Sellers JB, Merchant NB, Scoggins CR, Martin RC 3rd, Kim HJ, Ahmad S, Cho CS, Parikh AA, Chu CK, Hamilton NA, Doyle CJ, Pinchot S, Hayman A, McClaine R, Nakeeb A, Staley CA, McMasters KM, Lillemoe KD. A multicenter analysis of distal pancreatectomy for adenocarcinoma: is laparoscopic resection appropriate? J Am Coll Surg. 2010;210(5):779-85, 786-7.

17. Christein JD, Kendrick ML, Iqbal CW, Nagorney DM, Farnell MB. Distal pancreatectomy for resectable adenocarcinoma of the body and tail of the pancreas. J Gastrointest Surg. 2005;9(7):922-7.

18. Bilimoria KY, Tomlinson JS, Merkow RP, Stewart AK, Ko CY, Talamonti MS, Bentrem DJ. Clinicopathologic features and treatment trends of pancreatic neuroendocrine tumors: analysis of 9,821 patients. J Gastrointest Surg 2007;11:1460-1469.

19. Campana D, Nori F, Piscitelli L, Morselli-Labate AM, Pezzilli R, Corinaldesi R, Tomassetti P. Chromogranin A: is it a useful marker of neuroendocrine tumors? J Clin Oncol. 2007;25(15):1967-1973.

20. Kloppel G, Perren A, Heitz PU. The gastroenteropancreatic neuroendocrine cell system and its tumors: the WHO classification. Ann NY Acad Sci 2004;1014:13-27

21. Rindi G, Klöppel G, Alhman H, Caplin M, Couvelard A, de Herder WW, Eriksson B, Falchetti A, Falconi A, Komminoth P, Körner M,
Lopes JM, McNicol AM, Nilsson O, Perren A, Scarpa A, Scoazec JY, Wiedenmann B. TNM staging of foregut (neuro) endocrine tumors: a consensus proposal including a grading system. Virchows Arch 2006;449:395-401.

22. Bassi C, Dervenis C, Butturini G, Fingerhut A, Yeo C, Izbicki J, Neoptolemos J, Sarr M, Traverso W, Buchler M. Postoperative pancreatic fistula: an international study group (ISGPF) definition. Surgery 2005;138:8-13.

23. Briggs CD, Mann CD, Irving GRB, Neal CP, Peterson M, Cameron IC, Berry DP. Systematic review of minimally invasive pancreatic resection. J Gastrointest Surg 2009;13:1129-1137.

24. Gumbs AA, Grès P, Madureira FA, Gayet B. Laparoscopic vs. open resection of noninvasive intraductal pancreatic mucinous neoplasms. J Gastrointest Surg 2008;12:707-712.

25. Liang S, Hameed U, Jayaraman S. Laparoscopic pancreatectomy: Indications and outcomes. World J Gastroenterol. 2014;20(39): 14246-14254.

26. Tseng WH, Canter RJ, Bold RJ. (2011) Perioperative outcomes for open distal pancreatectomy: current benchmarks for comparison. J Gastrointest Surg 15:2053-2058.

27. Haugvik SP, Marangos IP, Røsok BI, Pomianowska E, Gladhaug IP, Mathisen O, Edwin B. Long-term outcome of laparoscopic surgery for pancreatic neuroendocrine tumors. World J Surg. 2013;37(3): 582-90.

28. Zureikat AH, Breaux JA, Steel JL, Hughes SJ. Can laparoscopic pancreaticoduodenectomy be safely implemented? J Gastrointest Surg 2011;15:1151e1157.

29. Rehman S, John S, Lochan R, Jaques BC, Manas DM, Charnley RM, French JJ, White SA. Oncological feasibility of laparoscopic distal pancreatectomy for adenocarcinoma: A single-institution comparative study. World J Surg 2014;38:476e483.

30. DiNorcia J, Schrope BA, Lee MK, Reavey PL, Rosen SJ, Lee JA, Chabot JA, Allendorf JD. Laparoscopic distal pancreatectomy offers shorter hospital stays with fewer complications. J Gastrointest Surg 2010; 14: 1804-1812

31. Fernandez-Cruz L, Cosa R, Blanco L, Levi S, López-Boado MA, Navarro S. Curative laparoscopic resection for pancreatic neoplasms: a critical analysis from a single institution. J Gastrointest Surg (2007) 11:1607-1621

32. Kang CM, Lee SH, Lee WJ. Minimally invasive radical pancreatectomy for left-sided pancreatic cancer: current status and future perspectives. World J Gastroenterol (2014) 20:2343-2351

33. Hu M, Zhao G, Wang F, Zhao Z, Li C, Liu R. Laparoscopic versus open distal splenopancreatectomy for the treatment of pancreatic body and tail cancer: a retrospective, mid-term follow-up study at a single academic tertiary care institution. Surg Endosc (2014) 28: 2584-2591

34. House MG, Cameron JL, Lillemoe KD, Schulick RD, Choti MA, Hansel DE, Hruban RH, Maitra A, Yeo CJ. (2006) Differences in survival for patients with resectable versus unresectable metastases from pancreatic islet cell cancer. J Gastrointest Surg 10: 138-145

35. Falconi M, Bartsch DK, Eriksson B, Kloppel G, Lopes JM, O'Connor JM, Salazar R, Taal BG, Vullierme MP, O'Toole D (2012) ENETS Consensus Guidelines for the management of patients with digestive neuroendocrine neoplasms of the digestive system: well-differentiated pancreatic non-functioning tumors. Neuroendocrinology 95(2):120-134

36. Abu Hilal M, Hamdan M, Di Fabio F, Pearce NW, Johnson CD (2012) Laparoscopic versus open distal pancreatectomy: a clinical and cost-effectiveness study. Surg Endosc 26(6):1670-1674 